\title{
George Gordon Habib, MB ChB, PhD, FRCP (Ed), FRCPC
}

$1920-1993$

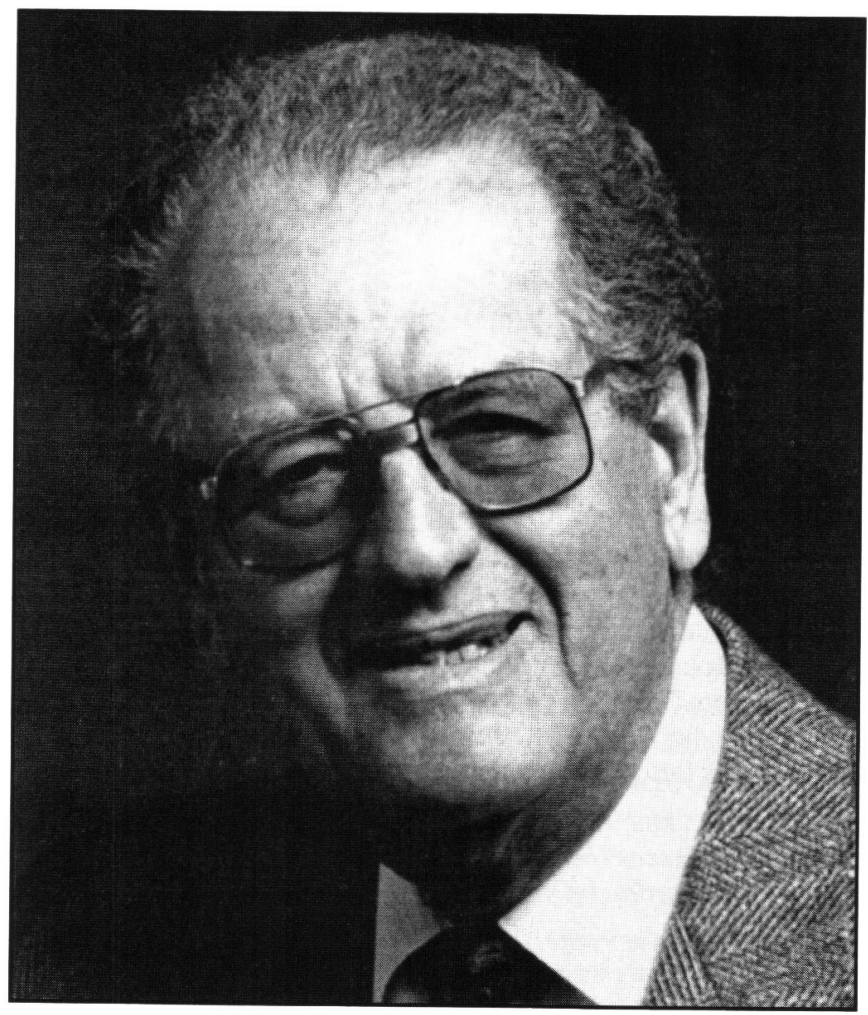

George Habib, a senior neurologist in the Department of Medicine, University of Manitoba, died on the 9th of September 1993, aged 73. Born in Trinidad, he had a distinguished academic career. He was educated at St. Mary's College, Port-of-Spain prior to commencing his medical studies. An Hons. BSc (Med) from McGill University was followed, in 1953, by graduation from the Medical College, Birmingham, England. Three subsequent years of clinical medicine in hospitals at Hereford and Bath, and a fourth year of general pathology at St. George's Hospital, London, preceded clinical appointments in the National Hospital, Queen Square, and the neurosurgical department at the Frenchay Hospital, Bristol.

When George returned to Trinidad as a physician to the General Hospital at San Fernando in 1959 his chief interests lay in the field of neurology and during his three years there, he published papers on the clinical aspects of aseptic meningitis, acute meningo-encephalitis, neurosyphilis, hereditary gingival fibromatosis, and Vit. B12 deficiency among the indigenous Hindus. It was during these years that he met Miss Irene Dickinson, the headmistress of a private school. George and Irene were married in September 1961 at Knutsford in Cheshire.

An appointment as Lecturer at the Edinburgh Medical College, in 1962, was followed by four years of neurological teaching and research. George presented a treatise entitled "The Effects of Morphine Upon the Central Control of Respiration" to the Post-Graduate Education Committee in 1966; this body recommended the award of the degree $\mathrm{PhD}$. Later the same year he accepted an invitation to join the Winnipeg Clinic, and so became its first neurologist. The following year, after his admission to Fellowship in the Canadian Royal College, he was elected to the neurological staff of the Department of Medicine, University of Manitoba.

By nature quiet, and always unobtrusive, George Habib was a thoughtful and methodical clinician. His Winnipeg Colleagues were soon made aware of the broad scope of his clinical knowledge, his great interest in the many advances then being made in neurological medicine and surgery, his often conservative approach to neurological problems, his shrewd clinical observations, and his compassionate concern for his patients' welfare. He shared with Irene a keen sense of humour, often being reduced to helpless mirth.

George had many forthright views, but he will be remembered for his courtesy and forbearance, his invariable optimism; and for the fortitude with which he faced a long illness. Irene, for thirty-two years a devoted wife, survives him.

Rankin Hay, Winnipeg, Manitoba 